\title{
Discharge flocking, a new method to disperse nano-particles
}

\author{
H. G. Lee ${ }^{1}$, J. H. Byun ${ }^{1}$, J. B. Kim ${ }^{1}$, J. W. Yi $^{1}$, W. Lee ${ }^{1}$, \\ B. K. Lee ${ }^{1}$, D. L. Cho ${ }^{2}$ \& M. D. Cho ${ }^{2}$ \\ ${ }^{1}$ Composite Materials Group, Korea Institute of Materials Science \\ (KIMS), Changwon, Korea \\ ${ }^{2}$ School of Applied Chemical Engineering \& Research Institute for \\ Catalysis, Chonnam National University, Gwangju, Korea
}

\begin{abstract}
One of the big challenges in the nano-field is how to effectively disperse nanoscale particles, especially CNTs and carbon blacks, which are strongly agglomerated by intermolecular van der Waals forces. Solution-based dispersion methods such as sonication and three-roll milling require lots of dispersion time and have re-agglomeration problems after processing. This study suggests a new method, i.e. discharge flocking, to disperse the particles effectively. Firstly nano-scale particles located between two electrodes, a negative electrode and a ground electrode, are charged by Townsend discharge. Next the negatively charged particles flow toward a target substrate by electric field generated by a positive electrode behind the substrate, and they are finally attached on the substrate. In contrast with the solution-based methods, this process makes nanoscale particles disperse in the air and repel each others because of their negative charges. Therefore, the re-agglomeration problem of processed particles could be prevented. In this study, carbon fiber reinforced epoxy composites including CNTs and carbon blacks were fabricated by the discharge flocking and the solution-based dispersion methods, respectively, and then their mechanical and electrical properties were compared with each other.
\end{abstract}

Keywords: discharge, flocking, nano-scale particles, strength, conductivity. 


\section{Introduction}

Recently how to effectively disperse nano-scale particles is one of the hot issues in fabricating nanocomposites. There are several solution-based methods to disperse nano-scale particles such as three-roll milling and sonication. However, the methods based on the mechanical forces such as high shear forces or ultrasonic vibrations spend lots of time to disperse nano-scale particles. Also when dispersed nano-scale particles should be dried, they might experience reagglomeration. Thus, this study suggests a new method dispersing nano-scale particles in the air within a short time by electric forces, i.e. discharge flocking named in this study.

Discharge flocking is a modification of electroflocking, combining corona discharge and electrostatic flocking. The former is a kind of electrical breakdown of gases facilitated by an electrode's geometric effect [1]. The sharp geometry of an electrode helps the breakdown occur more easily, resulting in lowering a breakdown voltage. The latter is a well-known method to fabricate thin film having vertically aligned short fiber layers $[2,3]$. Using high intensity electric field, the method induces the short fibers to polarize, and then the fibers move onto a target electrode. Transferring the fibers, the electric field pushes the fibers aligned according to electric line of force. In front of the electrode, the fibers are stacked with aligned state, i.e. so-called flocked, according to electric line of force whose direction is normal to the electrode. Then they are bonded by materials such as thermoset resin or molten thermoplastics. In discharge flocking, those two components, corona discharge and electrostatic flocking, were in charge of charging nano-scale particles with electrons and transferring the charged nano-scale particles, respectively.

Unlike traditional electroflocking using polarization phenomenon of nanoscale particles, discharge flocking manipulates direct electron charging phenomenon of nano-scale particles located inside corona discharge area. When corona discharge occurs, especially Townsend discharge region, there is flow of electrons in the air between two electrodes. Generally solids located inside this electron flow capture the electrons and then are charged negatively [3, 4]. If the mass of the solids is sufficiently low like that of nano-size particles, electrical repulsive forces between the electron flow and the solids push them out from the corona discharge area. Then the ejected nano-scale particles charged negatively are dispersed by electrical repulsive forces between each other.

After dispersing nano-scale particles, discharge flocking takes advantage of an electric field just like traditional electroflocking. In order to transfer negatively charged nano-scale particles onto a target substrate, an electrode with positive electric potential located behind the substrate attracts the nano-scale particles. The transferred particles could then be attached to the substrate by curing adhesive on the substrate. Following above process named as discharge flocking, nanocomposites having a good dispersion state can be fabricated in the air within a short time. 
In this study, carbon fabric reinforced epoxy matrix composites including well dispersed CNTs in the matrix was fabricated by discharge flocking with equipment designed by ourselves and by resin film infusion process with CNT dispersed B-stage epoxy resin film. Mechanical and electrical properties of the both composite specimens were measured and compared with each other.

\section{Specimens and experimental setup}

\subsection{Raw materials}

Nano-size particles used in this study are multi-walled CNTs (CM-95, Hanwha Nanotech, Korea) and carbon blacks (Ketjenblack EC300J, Mitsubishi Chemical, Japan). Their physical properties are shown in table 1. A resin mixture for Bstage film consists of epoxy resin (YD-128, Kukdo Chemical, Korea), a curing agent (DICY, Kukdo Chemical, Korea), an accelerator (DCMU, Kukdo Chemicals, Korea), and two kinds of solvents (DMF and MCS, Sam-chun Chemical, Korea), whose mixing ratios are $73.9: 3.5: 1.7: 10.5: 10.5$, respectively. The mixture's B-stage curing condition is dwelling of $10 \mathrm{~min}$ at $120^{\circ} \mathrm{C}$. Reinforced fibers for fabricating composites are plain woven carbon fabrics (NSN3k, SK Chemical, Korea). They physical properties of reinforced fibers and matrix are shown in table 2.

Table 1: $\quad$ Physical properties of nano-scale particles.

\begin{tabular}{c|c|c}
\hline Physical properties & $\begin{array}{c}\text { CNT } \\
(\mathrm{CM}-95)\end{array}$ & $\begin{array}{c}\text { Carbon black } \\
\text { (Ketjenblack EC300J) }\end{array}$ \\
\hline Density $\left[\mathrm{g} / \mathrm{cm}^{3}\right]$ & 1.8 & 2.1 \\
Surface area $\left[\mathrm{m}^{2} / \mathrm{g}\right]$ & 200 & 800 \\
Diameter $[\mathrm{nm}]$ & $10-15$ & 39.5 \\
Length $[\mu \mathrm{m}]$ & $10-20$ & - \\
\hline
\end{tabular}

Table 2: $\quad$ Physical properties of reinforced fibers and matrix.

\begin{tabular}{c|c|c}
\hline Physical properties & $\begin{array}{c}\text { Plain woven carbon } \\
\text { fabric } \\
\text { (NSN3k) }\end{array}$ & $\begin{array}{c}\text { Epoxy } \\
\text { (YD-128) }\end{array}$ \\
\hline Density $\left[\mathrm{g} / \mathrm{cm}^{3}\right]$ & 1.8 & 1.2 \\
Elastic Modulus [GPa] & 240 & 3.4 \\
Strength [MPa] & 4800 & 87 \\
Areal weight $\left[\mathrm{g} / \mathrm{m}^{2}\right]$ & 200 & - \\
Thickness $[\mathrm{mm}]$ & 0.25 & - \\
\hline
\end{tabular}




\subsection{Dispersion}

\subsubsection{Discharge flocking}

Fig. 1 shows the equipment for discharge flocking designed in this study. As shown in fig. 1(a), nano-scale particles (CNTs or carbon blacks) are positioned on the GND electrode. The first step is charging process. Applying $-25 \mathrm{kV}$ to the discharge electrode and $-12 \mathrm{kV}$ to the transfer electrode causes corona discharge, especially Townsend discharge region. The discharge makes electrons flow from the discharge electrode to the GND electrode, and its current level is about $0.1 \mathrm{~mA}$. Then the nano-scale particles on the GND electrode are charged negatively by capturing the electrons. Strong electric repulsive forces between the negatively charged particles and the electron flow throw the particles out from the corona discharge area. The ejected particles are then dispersed by electric repulsive forces among them. The next step is transferring process. Applying $+5 \mathrm{kV}$ to the transfer electrode after finishing charging process attracts the negatively charged nano-scale particles to the substrate located in front of the transfer electrode. In this study, plain woven carbon fabric/B-stage epoxy resin prepreg was used for the substrate. Finally, after transferring process the substrate is heated up to $80^{\circ} \mathrm{C}$ and dwells for $10 \mathrm{~min}$ in order to immerse the flocked nano-scale particles in the epoxy resin.

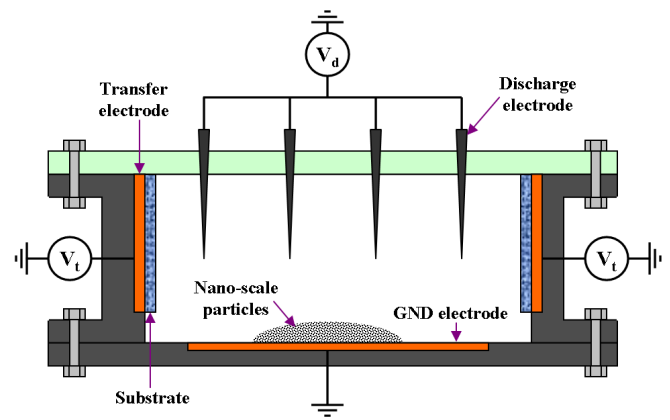

(a)

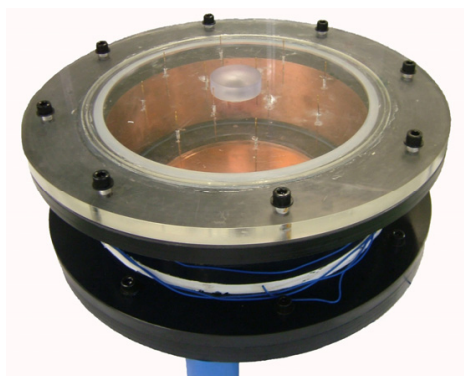

(b)

Figure 1: Equipment for discharge flocking: (a) schematic diagram; (b) its photograph. 


\subsubsection{Three-roll milling}

Fig. 2 represents a schematic diagram of a three-roll mill (Model 80E, Exakt, Germany). The three-roll mill is operated at $250 \mathrm{rpm}$ under a force mode while feeding an epoxy resin mixture with nano-scale particles. After repeating the three-roll milling five times, the resin mixture with well dispersed nano-scale particles is casted with the thickness of $300 \mu \mathrm{m}$ on release coated backup film. Finally, through heating up the casted resin film and its dwelling for $10 \mathrm{~min}$ at $120^{\circ} \mathrm{C}$, it becomes nano-scale particle dispersed B-stage epoxy resin film.

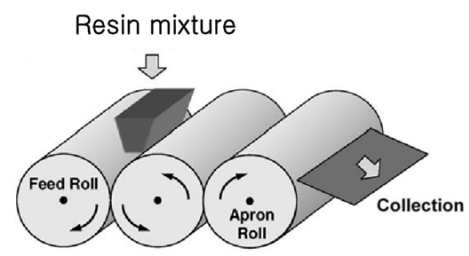

Figure 2: Schematic diagram of a three-roll mill.

\subsection{Specimen fabrication}

The fabrication method of specimens used in this study is shown in fig. 3. Seven plies of carbon fabric epoxy prepreg treated with the discharge flocking on its one surface and a ply of untreated one are consecutively stacked. Also nine plies of nano-scale particle dispersed B-stage epoxy resin films and eight plies of plain woven carbon fabrics are alternately stacked. The both stacked laminates are positioned in the mold as shown in fig. 3, and then the mold is sealed in order to apply vacuum to it. The mold is heated up by hot press (CMV50H-18-CLX, Carver, USA) and experiences curing cycle as shown in fig. 4. When dwelling

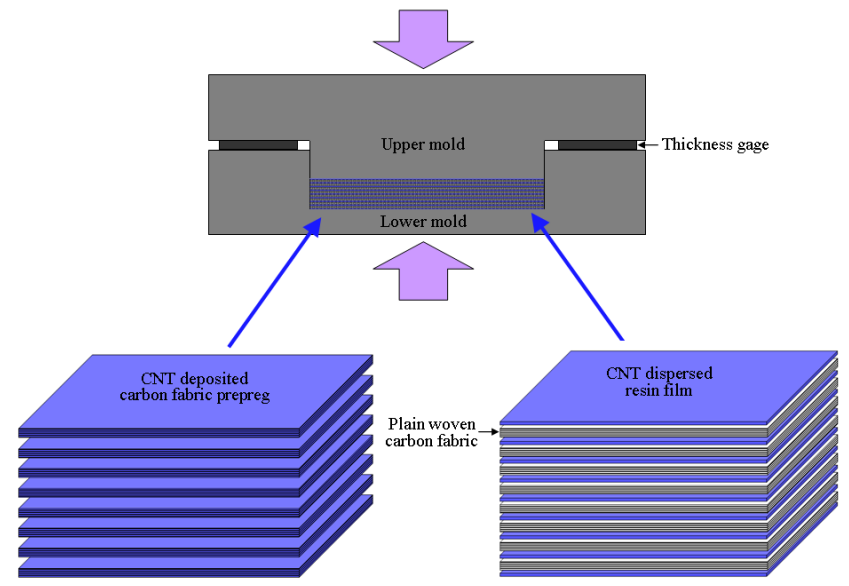

Figure 3: Schematic diagram of fabricating specimen using hot press molding. 


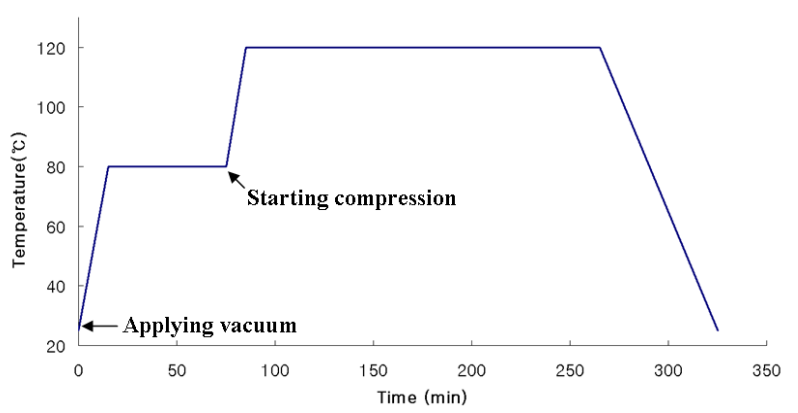

Figure 4: Curing cycle of stacked laminates.

of 60 min at $80^{\circ} \mathrm{C}$ makes the viscosity of epoxy resin in the stacked laminates sufficiently low, the hot press applies compressive forces to the mold in order to squeeze out excessive resin from the prepreg laminates or to make resin penetrate the plain woven carbon fabrics located between the epoxy resin films (i.e. resin film infusion process). After dwelling of $180 \mathrm{~min}$ at $120^{\circ} \mathrm{C}$, the epoxy in the laminates is fully cured. In this study the cured laminates were molded with the thickness of $2 \mathrm{~mm}$ by inserting thickness gages between the upper and the lower mold as shown in fig. 3, resulting in the carbon fabrics' volume fraction in the fabricated laminates being $44 \%$.

Now two kinds of specimens, one for measuring mechanical properties and the other for measuring electrical properties, are machined out from the cured laminates by diamond wheel cutter. In this study their cutout dimensions were $13 \mathrm{~mm} \times 4 \mathrm{~mm} \times 2 \mathrm{~mm}$ and $15 \mathrm{~mm} \times 15 \mathrm{~mm} \times 2 \mathrm{~mm}$, respectively. For the specimens to measure electrical properties, the resin reach area on their surfaces should be ground in order to make carbon fibers in the fabrics be able to contact with an electrode material. Thus the final dimensions of the specimens for measuring electrical properties were $15 \mathrm{~mm} \times 15 \mathrm{~mm} \times 1.8 \mathrm{~mm}$.

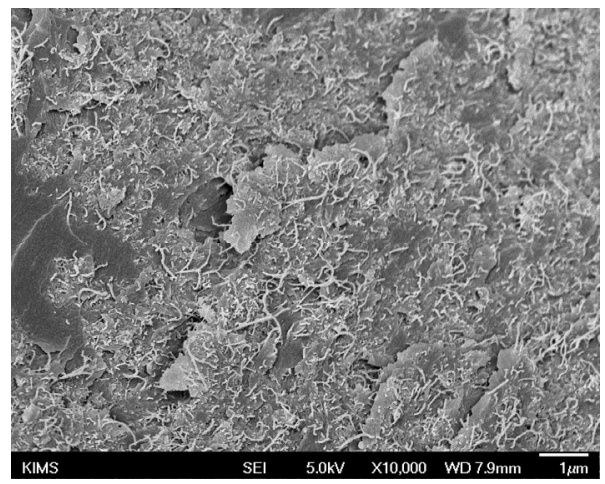

Figure 5: FE-SEM photograph of CNTs' dispersion in the specimen fabricated by discharge flocking. 
Fig. 5 shows the FE-SEM (Field Emission Scanning Electron Microscope) photograph of CNTs' dispersion in the specimen fabricated by discharge flocking. The CNTs, white fibers shown in fig. 5, are well dispersed in the epoxy matrix.

\subsection{Measuring equipment}

A digital multimeter (Model 2100, Keithley, USA) was used to measure the specimen's electrical conductivities according to in-plane direction and throughthe-thickness direction as shown in fig. 6. The equations to calculate the specimen's electrical conductivity $\sigma$ are as follows:

$$
\begin{gathered}
\sigma=\frac{1}{\rho} \\
\rho=\frac{R A}{\ell}
\end{gathered}
$$

where, $\rho$ is the electrical resistivity, $R$ is the measured resistance of the specimen, and $A$ is the area of the specimen.

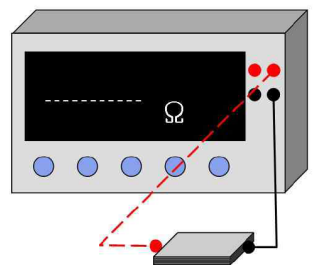

(a)

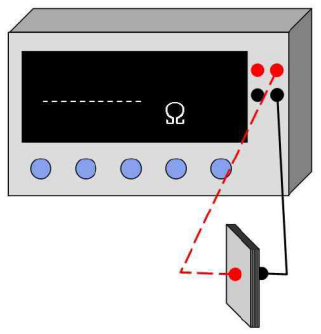

(b)

Figure 6: Schematic diagram of measuring conductivity by digital multimeter: (a) in-plane direction, (b) through-the-thickness direction.

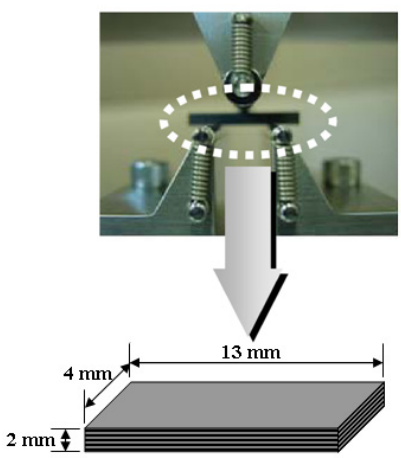

Figure 7: Three point bending test for measuring the short beam shear strengths of the specimens. 
A universal testing machine (Model 5882, Instron, USA) was used to measure the specimens' short beam shear strengths, following ASTM D2344. Fig. 7 shows a three point bending test performed in this study for measuring the strengths.

\section{Results and discussion}

\subsection{Electrical properties of the specimens}

Fig. 8 represents measured electrical conductivities of the specimens according to in-plane direction and through-the-thickness direction. The black circles in the graph are average values of 5 experimental data at the three specimen conditions, and the vertical bars passing through the circles represent the data's ranges. The CNTs' areal density between two adjacent carbon fabric layers was $2.1 \mathrm{~g} / \mathrm{m}^{2}$ in both the cases, discharge flocking and resin film. The in-plane conductivities of the specimens without CNTs, fabricated by discharge flocking, and fabricated by resin film infusion were $51.2 \mathrm{~S} / \mathrm{cm}, 70.3 \mathrm{~S} / \mathrm{cm}$, and $72.2 \mathrm{~S} / \mathrm{cm}$,

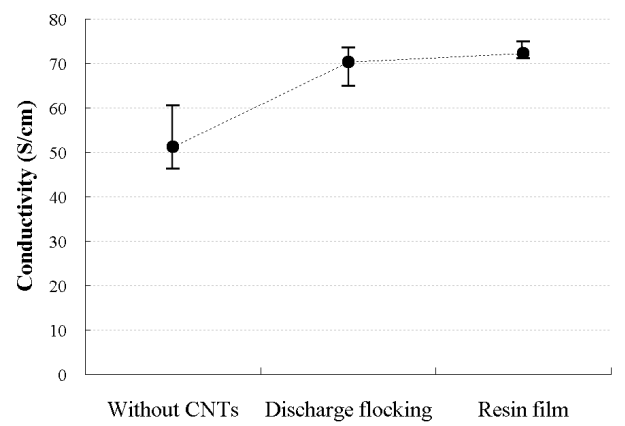

(a)

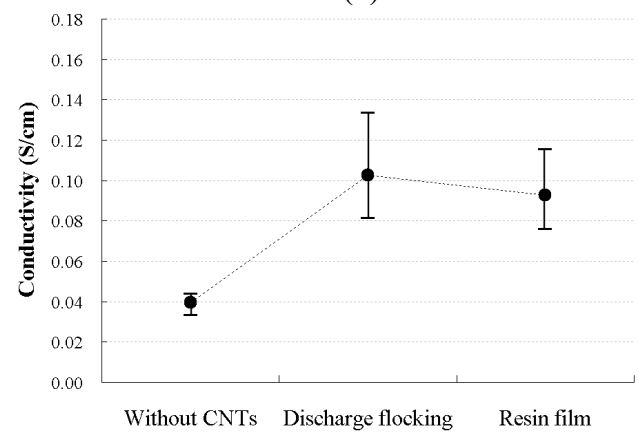

(b)

Figure 8: Measured electrical conductivities of the specimens in which CNTs' areal densities between two adjacent carbon fabric layers are $2.1 \mathrm{~g} / \mathrm{m}^{2}$ : (a) according to in-plane direction, (b) according to through-the-thickness direction. 
respectively. The through-the-thickness conductivities of the specimens without CNTs, fabricated by discharge flocking, and fabricated by resin film infusion were $0.040 \mathrm{~S} / \mathrm{cm}, 0.103 \mathrm{~S} / \mathrm{cm}$, and $0.093 \mathrm{~S} / \mathrm{cm}$, respectively. Since the specimens fabricated by discharge flocking and by resin film infusion had the same CNTs' weight fraction, the specimens' conductivities according to both the directions enhanced by the almost same amounts.

Fig. 9 gives us information on the different effects of CNTs and carbon blacks on the specimens' directional conductivities. Two kinds of specimens were fabricated by discharge flocking with the CNT only condition and the half and half CNT/carbon black mixture condition. Each specimen has the same value of $2.1 \mathrm{~g} / \mathrm{m}^{2}$ nano-scale particles' areal density. The black and red circles in the graph are average values of 5 experimental data at each condition. The throughthe-thickness conductivity of the first condition is lower than that of the second condition, but the in-plane conductivity of the first condition is higher than that of the second condition. Usually carbon blacks whose shape is like agglomerated small spheres with the diameter of $39.5 \mathrm{~nm}$ have no directional conductivity, but CNTs whose shape is a long fiber with the diameter of $10-15 \mathrm{~nm}$ and the length of $10-20 \mu \mathrm{m}$ have strong directional conductivity according to the fiber direction. If the direction of CNTs in the specimen has random distribution, then overall conductivity of the specimen has no directional tendency just like the specimen having carbon blacks. Conversely if the conductivity of the specimen having CNTs has directional tendency, then it could be said that the distribution of the CNTs in the specimen is not random distribution but directional distribution according to the direction having high conductivity. In fig. 9, unlike the half and half CNT/carbon black mixture condition that includes carbon blacks' isotropic tendency in conductivity, the CNT only condition has higher in-

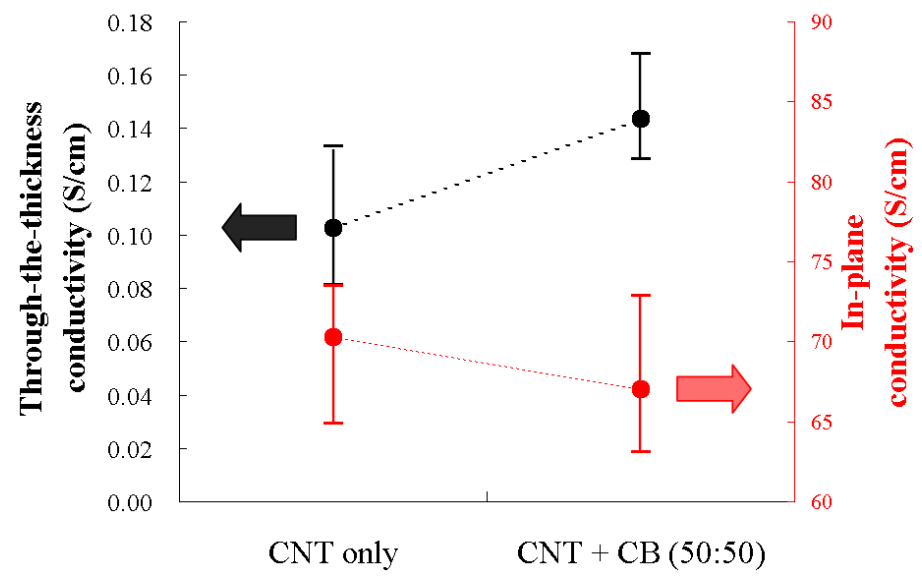

Figure 9: Measured electrical conductivity of the specimens fabricated by discharge flocking with different nano-scale particles, CNT only and CNT + carbon black, whose areal densities have the same value of $2.1 \mathrm{~g} / \mathrm{m}^{2}$. 
plane conductivity and lower through-the-thickness conductivity than does the other. Thus, it could be inferred that the CNTs in the specimen that experienced compression of flocked prepreg laminates in this study are distributed mainly according to the in-plane direction.

\subsection{Mechanical properties of the specimens}

Fig. 10 shows measured short beam strengths of the fabricated specimens. The black circles in the graph are average values of 5 experimental data at each condition. The carbon fabric epoxy matrix composite specimen without CNTs had the short beam shear strength of 66.7 MPa. When CNTs were inserted into each composite layer up to $2.1 \mathrm{~g} / \mathrm{m}^{2}$ areal density by discharge flocking, the composites' short beam shear strength was 73.0 MPa, which was $9.3 \%$ higher than that of the specimen without CNTs. When CNTs were inserted by resin film infusion up to $2.1 \mathrm{~g} / \mathrm{m}^{2}$ areal density, the composites' short beam shear strength was $72.2 \mathrm{MPa}$, which was $8.2 \%$ higher than that of the specimen without CNTs. Since the enhancement of the composites' short beam shear strength by two methods had the almost same value, it could be concluded that the discharge flocking process would be able to increase the composite short beam shear strength at least by the amount the resin film infusion process can do.

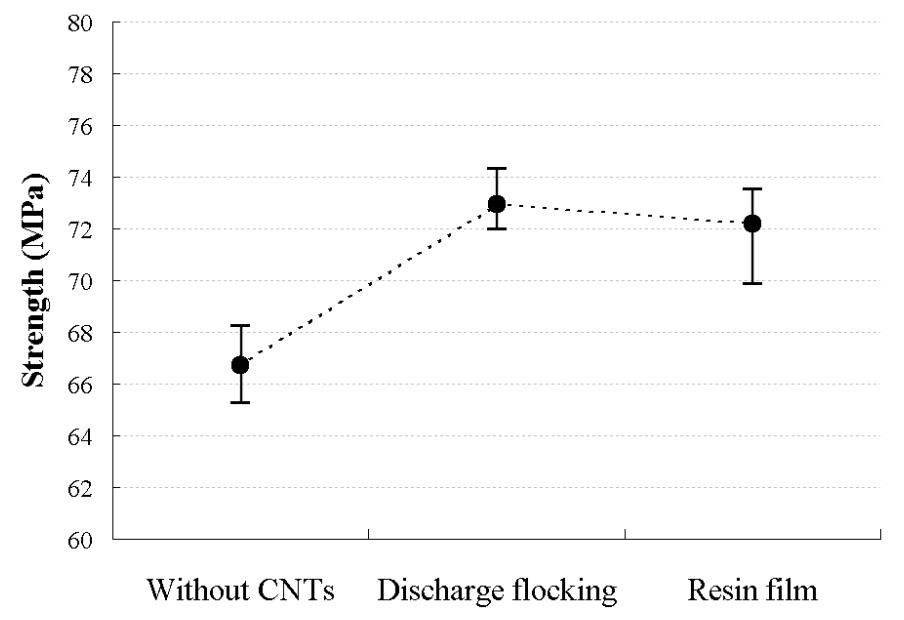

Figure 10: Short beam shear strengths of the fabricated specimens.

\section{Conclusion}

In this study, suggested was a new dispersion method of nano-scale particles using electrostatic flocking and corona discharge, i.e. discharge flocking. In order to evaluate the new method, CNTs' dispersion state in the carbon fabric epoxy composite specimens was inspected by SEM, and the electrical and 
mechanical properties of the composite specimens including nano-scale particles were measured and compared. From the experiment of measuring electrical conductivities and short beam shear strengths, it was found that during compression of laminates CNTs are slightly aligned according to in-plane direction and the discharge flocking process can increase the composite short beam shear strength at least by the amount the resin film infusion process can do.

\section{Acknowledgement}

This study was performed as a part of Global Research Laboratory Program supported by the Korea Foundation for International Cooperation of Science \& Technology (KICOS) through a grant provided by the Korean Ministry of Education, Science \& Technology (MEST) in 2007 (No. K20704000090).

\section{References}

[1] Lim, S.H., Lee, S.S., Park, M., Kim, J.K., Choe, C.R. \& Kwon, S.J., Manufacture of short fiber prepreg using electroflocking, Proceeding of KSCM Conference Autumn 2002, pp. 288-291, 2002.

[2] Mironov, V.S. \& Park, M., Electroflocking technique in the fabrication and performance enhancement of fiber-reinforced polymer composites, Composite Science and Technology, 60, pp. 927-933, 2000.

[3] Meek, J.M. \& Craggs, J.D., Electrical Breakdown of Gases, John Wiley \& Sons, Ltd., New York, 1978.

[4] Park, M., Kim, J.K., Lim, S.H., Ko, M.B. \& Choe, C.R., Charging behavior of chopped carbon fibers under high intensity electric fields, Korea Polymer Journal, 8(1), pp. 6-11, 2000. 